\title{
Visualization of Hypoxia-Inducible Factor-1 Transcriptional Activation in C6 Glioma Using Luciferase and Sodium Iodide Symporter Genes
}

\author{
Chan Joo Yeom ${ }^{1,2}$, June-Key Chung ${ }^{1,2}$, Joo Hyun Kang ${ }^{3}$, Yong Hyun Jeon ${ }^{1,2}$, Kwang Il Kim ${ }^{1,2}$, Yong Nan Jin ${ }^{1}$, \\ You Mie Lee ${ }^{4}$, Jae Min Jeong ${ }^{1,2}$, and Dong Soo Lee ${ }^{1,2}$ \\ ${ }^{I}$ Department of Nuclear Medicine, Tumor Immunity Medical Research Center, Laboratory of Molecular Imaging and Therapy of Cancer \\ Research Institute, Seoul National University College of Medicine, Seoul, Korea; ${ }^{2}$ Institute of Radiation Medicine, Medical Research \\ Center, Seoul National University, Seoul, Korea, ${ }^{3}$ Laboratory of Nuclear Medicine, Korea Institute of Radiological and Medical Science, \\ Seoul, Korea; and ${ }^{4}$ Kyungpook National University College of Nature Sciences, Daegu, Korea
}

\begin{abstract}
Hypoxia-inducible factor-1 (HIF-1) is a transcription factor of hypoxic response in cancer cells and is associated with tumor progression, angiogenesis, metastasis, and resistance to therapy. We assessed whether the human sodium iodide symporter (NIS) reporter systems can be used to visualize transcriptional activation of HIF-1 in C6 glioma. Methods: Two types of plasmidexpressing human NIS or luciferase (LUC) genes, controlled by 5 copies of hypoxia response element (5HRE), were constructed: p5HRE-NIS or p5HRE-Luc. C6 glioma cells were stably transfected with p5HRE-NIS or p5HRE-Luc plasmids (C6-5HRE-NIS or C6-5HRE-Luc). Hypoxic conditions were modeled by exposing culture medium to desferrioxamine (DFO) or a low oxygen atmosphere $\left(<1 \% \mathrm{O}_{2}\right)$ in a hypoxic chamber. HIF-1 transcription activity was assessed by measuring cellular ${ }^{125}$ I uptake and luminescent intensities. Reverse-transcription polymerase chain reaction and Western blotting were performed to observe the messenger RNA and protein levels of reporter and target genes under hypoxic or normoxic conditions. C6, C6-cytomegalovirus (CMV)-NIS, or C6-CMV-Luc and C6-5HRE-NIS or C6-5HRELuc cells were injected subcutaneously into nude mice (the NIS and Luc groups, respectively). Two weeks after tumor challenge, bioluminescence and ${ }^{99 \mathrm{~m}} \mathrm{Tc}$ scintigraphic images were acquired before and after intraperitoneal DFO administration. Natural hypoxia in tumors was induced by growing tumors for 3 wk. Ex vivo studies, such as biodistribution, immunohistochemistry, and $99 \mathrm{mTC}$ autoradiography, were performed. Results: Timeand concentration-dependent increases of ${ }^{125}$ I uptake and bioluminescence were observed in hypoxically stressed reporter cells. Also, messenger RNA and protein levels of reporter and target genes increased under hypoxic conditions. ${ }^{99 m T c}$ uptake and bioluminescence signals from C6-5HRE-NIS and C6-5HRE-Luc tumors increased during hypoxia. In the biodistribution study, a larger amount of ${ }^{99 \mathrm{mTC}}$ accumulated in C6-5HRE-NIS tumors than in the other tumors not containing 5HRE $(P<0.005)$. In the Luc group, immunostaining showed similar distribution patterns for luciferase and pimonidazole, and in the NIS group, autoradiog-
\end{abstract}

\footnotetext{
Received Jun. 21, 2007; revision accepted May 20, 2008.

For correspondence or reprints contact: June-Key Chung, Department of Nuclear Medicine, Seoul National University College of Medicine, 28 Yongondong, Chongno-gu, Seoul, 110-744, Korea.

E-mail: jkchung@plaza.snu.ac.kr

COPYRIGHT @ 2008 by the Society of Nuclear Medicine, Inc.
}

raphy of C6-5HRE-NIS tumors showed a distribution similar to that observed for pimonidazole immunostaining. Conclusion: The transcriptional activation of HIF-1 induced by hypoxia or DFO was visualized by both bioluminescence and scintigraphic reporter gene systems.

Key Words: hypoxia; hypoxia-inducible factor-1; molecular imaging; sodium iodide symporter; luciferase

J Nucl Med 2008; 49:1489-1497

DOI: 10.2967/jnumed.107.044461

O olid tumors usually contain hypoxic tissues due to a combination of uncontrolled cell proliferation and insufficient and abnormal vascularization. Cancer cells express many genes to survive in anaerobic environments, and hypoxiainducible transcription factor-1 (HIF-1) is a key mediator. HIF-1 regulates the expressions of many hypoxia-inducible genes and thus facilitates adaptive response. HIF-1 is a heterodimer composed of an HIF-1 $\alpha$, whose expression is dependent on cellular oxygen level, and a constitutively expressed HIF$1 \beta$ (aryl hydrocarbon receptor nuclear translocator) (1-3).

$\mathrm{HIF}-1 \alpha$ reacts quite differently at different cellular oxygen levels. Under normoxic conditions, the von Hippel-Lindau protein recognizes posttranslational modifications caused by iron or the oxygen-dependent hydroxylation of HIF- $1 \alpha$ and induces the ubiquitin proteasomal degradation pathway; thus, it blocks the transcription of target genes. On the other hand, under hypoxic conditions, HIF- $1 \alpha$ is activated through a multistep process involving its stabilization, nuclear translocation, and heterodimerization with the HIF- $1 \beta$ subunit. In addition, HIF- $1 \alpha \beta$ binds to a cis-acting hypoxia response element (HRE) of the consensus sequence in the upstream site of more than 60 genes, which are also involved in cell proliferation and survival, tumor therapy resistance, glucose metabolism (e.g., glucose transporter 1), angiogenesis (e.g., vascular endothelial growth factor $[V E G F])$, metastasis, and apoptosis $(2,4-7)$. 
HIF- $1 \alpha$ can also be upregulated via other mechanisms. For example, the inactivation of the von Hippel-Lindau tumor suppressor gene increases HIF- $1 \alpha$ stabilization (8), and HIF$1 \alpha$ protein synthesis can be induced in an oxygen-independent manner, such as by the phosphatidylinositol 3-kinase and mitogen-activated protein kinase pathways, which are stimulated by growth factors, cytokines, and other signaling molecules (4). Cobalt chloride or iron chelators such as desferrioxamine (DFO) also stabilize HIF-1 $\alpha$ by blocking HIF- $1 \alpha$ posttranslational modification by prolyl hydroxylase $(9,10)$.

Several methods have been developed to measure hypoxia or HIF-1 activation in solid tumors. Commonly used invasive methods include microelectrode oxygen concentration measurements (11), immunohistochemical stainings for pimonidazole (an exogenous hypoxic marker) $(12,13)$, carbonic anhydrase IX (14), and HIF-1 $\alpha$ (15). In noninvasive methods, molecular imaging based on nuclear medicine and optical imaging systems offers another approach. Some investigators have tried to visualize tumor hypoxia by imaging ${ }^{18} \mathrm{~F}$-fluoroerythronitroimidazole or ${ }^{18} \mathrm{~F}$-fluoromisonidazole (FMISO) using PET techniques (16). Recently, a cispromoter reporter gene imaging system was used to visualize hypoxia. ${ }^{124} \mathrm{I}-2^{\prime}$-fluoro-2'-deoxy-1 $\beta$-D-arabinofuranosyl5-iodouracil accumulates in hypoxic cells that express exogenously the HIF- $1 \alpha$-driven herpes simplex virus type 1 thymidine kinase gene (16). In addition, luciferase (13) and green fluorescence protein (17) have been used for optical imaging.

The sodium iodide symporter (NIS) gene is an imaging reporter gene used in nuclear medicine. NIS is an integral membrane protein and cotransports 2 sodium ions and 1 iodide ion into cells in normal thyroid tissue and in some nonthyroid tissues, such as salivary glands, stomach, thymus, and breast. As compared with conventional PET reporter genes, NIS has several advantages because it has a wide availability of substrates, such as the radioiodine ${ }^{99 \mathrm{~m}} \mathrm{Tc}$-pertechnetate. Moreover, these substrates are unlikely to influence the underlying cell biochemistry and accordingly are not metabolized in most tissues (18). Our groups and others have described the usefulness of NIS in the visualization of molecular-genomic phenomena, including gene expression, nuclear receptor activation, and target cell trafficking $(19,20)$.

The purpose of the present study was to develop an NIS gene system to noninvasively image HIF-1 transcriptional activation in C6 rat glioma. Firefly luciferase (Luc) and human sodium iodide symporter $(h N I S)$ reporter genes were used for bioluminescence and scintigraphic imaging, and HIF-1-specific reporter systems were engineered using the $h N I S$ and Luc genes. These systems were used to compare patterns of reporter gene expression with those of conventional hypoxic markers.

\section{MATERIALS AND METHODS}

\section{DNA Constructs}

DNA fragments encoding $h N I S$ (kindly provided by Dr. Sissy Jhiang of Ohio State University) were inserted between BamH I and
Xho I sites of the pcDNA3 vector (Invitrogen) to construct the plasmid pCMV-NIS. Luciferase was cloned from the pGL2 vector (Promega) and inserted between Sal I and Not I sites of the pIRES vector (Clontech) to construct the plasmid pCMV-Luc. The cytomegalovirus (CMV) promoter located between Nru I and Hind III sites was removed from pCMV-NIS. The cDNA fragment bearing 5 repeats of HRE (HRE; CCACAGTGCATACGTGGGCTCCAACAGGTCCTCTT) from $h V E G F$ and minimal SV40 promoter (5HRE) were prepared from the pGL2-5HRE-Luc plasmid (kindly provided by Dr. You Mie Lee (21)) by polymerase chain reaction (PCR) using the following primers: 5'-CCTAACTAGTCGTTCCCACAGTGCATAC-3' (forward primer) and 5'-CCTAGCTAGCCAGTACCGGAATGCCAAG-3' (reverse primer). PCR products were released by $\mathrm{Nru}$ I and Hind III and inserted into pCMV-NIS (described above) to construct the p5HRE-NIS plasmid (Fig. 1A).

To construct p5HRE-Luc (Fig. 1B), 5HRE fragments were prepared by PCR using the following primers: 5'-CCTATTCATATGCGTTCCCACAGTGCATAC-3' (forward primer) and 5' -CCTATTGCTAGCCAGTACCGGAATGCCAAG-3' (reverse primer). The CMV promoter of pCMV-Luc was replaced with the PCR products of 5HRE released by Nde I and Nhe I.

\section{Cell Culture and Hypoxia}

C6 rat glioma cells (CCL-107; American Type Culture Collection) were cultured in Dulbecco's modified Eagle's medium (Gibco) containing $1 \%$ antibiotic-antimycotic solution (10,000 IU of penicillin, $10,000 \mu \mathrm{g}$ of streptomycin per milliliter, $25 \mu \mathrm{g}$ of amphotericin B per milliliter [Cellgro], and $10 \%$ [v/v] fetal bovine serum [Invitrogen]). Cells were cultured under normoxic conditions (5\% $\mathrm{CO}_{2}, 20 \% \mathrm{O}_{2}$, and $75 \% \mathrm{~N}_{2}$ ) in a humidified chamber at $37^{\circ} \mathrm{C}$ or under hypoxic conditions $\left(<1 \% \mathrm{O}_{2}\right)$ in a hypoxic chamber, or they were treated with various concentrations $(0-400 \mu \mathrm{M})$ of DFO for 4-24 h. To evaluate cell viability, normoxic and hypoxic cells were washed with $1 \times$ phosphate-buffered saline (PBS), trypsinized and mixed with the same volume of trypan blue solution $(0.4 \%, \mathrm{w} / \mathrm{v}$, in PBS), and immediately examined to determine whether they excluded the dye under light microscopical observation. The number of dead stained cells was counted, and percentage of cell viability was obtained.

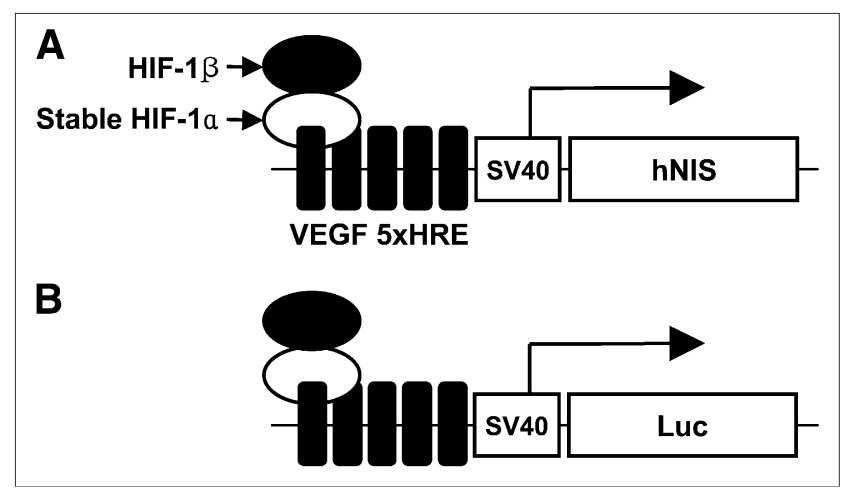

FIGURE 1. Diagram of HIF-1 specifically expressed $h N I S$ or Luc reporter gene system. Expression of $h N I S(A)$ or Luc (B) gene is regulated by $5 \mathrm{HRE}$ (5xHRE) from human VEGF and SV40 promoter. Under hypoxic conditions, HIF- $1 \alpha \beta$ complex binds $5 \mathrm{HRE}$ and induces transcriptional expression of reporter genes. 


\section{Establishment of Stable Cell Lines}

C6 glioma cells were transfected with p5HRE-NIS (or p5HRELuc) using LipofectAMINE Plus reagent (Invitrogen) according to the manufacturer's instructions. Cells were cultured in medium supplemented with $400-850 \mu \mathrm{g}$ of geneticin per milliliter (Invitrogen) to select stable transfectants for $2 \mathrm{wk}$. Established clonal lines were screened using ${ }^{125} \mathrm{I}$ uptake assay and bioluminescence assays, and after hypoxia had been induced in a hypoxic chamber $\left(<1 \% \mathrm{O}_{2}\right)$ for $24 \mathrm{~h}$ the C6-5HRE-NIS or C6-5HRE-Luc clone with the highest iodide uptake and bioluminescent activity was isolated.

\section{In Vitro ${ }^{125}$ I Uptake Assay}

To assess hypoxia-inducible hNIS activity, ${ }^{125}$ I uptake levels were determined using a modification of the method described by Weiss et al. (22). C6-5HRE-NIS reporter cells were seeded at $1 \times 10^{5}$ cells per well in 24-well plates in Dulbecco's modified Eagle's medium containing $10 \%$ fetal bovine serum. After $24 \mathrm{~h}$, cells were treated with DFO at 100, 200, or $400 \mu \mathrm{M}$ (Sigma Chemical Co.) or exposed to hypoxia $\left(<1 \% \mathrm{O}_{2}\right)$ for various times $(4,8,12$, or $24 \mathrm{~h})$ to activate HIF- $1 \alpha$. The cells were then treated with $0.5 \mathrm{~mL}$ of Hanks' balanced salt solution containing $0.5 \%$ bovine serum albumin, $10 \mathrm{mM}$ 2-[4-(2-hydroxyethyl)-1-piperzinyl] ethanesulfonic acid- $\mathrm{NaOH}(\mathrm{pH}$ 7.3), $10 \mu \mathrm{M}$ sodium iodide, and carrier-free $\mathrm{Na}^{125} \mathrm{I}$ (at a specific activity of $3.7 \mathrm{kBq}[0.1 \mu \mathrm{Ci}])$ at $37^{\circ} \mathrm{C}$ for $30 \mathrm{~min}$. The cells were then washed twice rapidly with $2 \mathrm{~mL}$ of ice-cold iodide-free Hanks' balanced salt solution buffer and detached with $0.2 \%$ sodium dodecyl sulfate, and radioactivities were measured using a $\gamma$-counter. Uptake values were normalized versus the percentage of viable cells present as determined by trypan blue exclusion assays.

\section{In Vitro Bioluminescence Assays}

Bioluminescence assays were performed using a luciferase assay kit (Tropix). Cells were plated and treated with DFO or incubated in a hypoxic chamber, as described previously. After induction of hypoxic conditions, cells were washed twice with $1 \mathrm{~mL}$ of $1 \times \mathrm{PBS}$, and lysis solution was then added to each well. Cell lysates were transferred to a microplate, and bioluminescences were measured using a Wallac 1420 VICTOR3 V (PerkinElmer Life and Analytic Sciences). Bioluminescent signals were normalized versus the percentage of viable cells present as determined by trypan blue exclusion assays.

\section{Reverse-Transcription PCR (RT-PCR) Analysis of Transcripts from $h N I S$, Luc, and VEGF Genes Specifically Targeted by HIF-1}

C6 parental cells and C6-CMV-NIS (the expression of the hNIS gene is controlled by CMV independently of hypoxia) or C6-CMVLuc (the expression of the Luc gene is controlled by CMV independently of hypoxia) cells and C6-5HRE-NIS or C6-5HRELuc reporter cells were incubated under normoxic or hypoxic $(<1 \%$ $\mathrm{O}_{2}$ ) conditions for $24 \mathrm{~h}$, harvested, and lysed with Trizol reagent (Invitrogen). Total RNA was extracted according to the manufacturer's instructions. cDNAs were synthesized in a final volume of 20 $\mu \mathrm{L}$ using $1 \mu \mathrm{g}$ of total RNA, $1 \mu \mathrm{L}$ of random primer $\mathrm{p}(\mathrm{dN}), 4 \mu \mathrm{L}$ of $5 \times$ first strand buffer, $2 \mu \mathrm{L}$ of $0.1 \mathrm{M}$ dithiothreitol, $1 \mu \mathrm{L}$ of $10 \mathrm{mM}$ deoxynucleotide triphosphate mix, $1 \mu \mathrm{L}$ of RNase inhibitor, and $1 \mu \mathrm{L}$ of SuperScript II reverse transcriptase (Invitrogen). To quantify VEGF and $h N I S$ (or luciferase) messenger RNA (mRNA) expressions (both of which are downstream genes of 5HRE under normoxic or hypoxic conditions), the prepared cDNAs were subjected to PCR by using primers for $h N I S$ (or $L u c$ ), VEGF, and $\beta$-actin as an internal control. The primer sequences used were as follows:
5'-CTACGAGTACCTGGAGATGC-3' (NIS forward),

5'-GTCGCAGTCAGTGTAGAACA-3' (NIS reverse),

5'-ATGGAAGACGCCAAAAACATAA-3' (Luc forward),

5'-TTACAATTTGGACTTTCCGCC-3' (Luc reverse),

5'-ATGGACGTCTACCAGCGCAGC-3' (VEGF forward),

5'-GTCACATCTGCAAGTACGTTCG-3' (VEGF reverse),

5'-TGACGGGGTCACCCAACTGTGCCCATCTA-3' ( $\beta$-actin forward), and

5'-CTAGAAGCATTTGCGGTGGACGATGGAGGG-3' ( $\beta$-actin reverse).

PCR was performed using an initial denaturation at $95^{\circ} \mathrm{C}$ for 10 min, 25 amplification cycles $\left(30 \mathrm{~s}\right.$ at $94^{\circ} \mathrm{C}, 30 \mathrm{~s}$ at $55^{\circ} \mathrm{C}$, and $1 \mathrm{~min}$ at $72^{\circ} \mathrm{C}$ ), and a final extension at $73^{\circ} \mathrm{C}$ for $7 \mathrm{~min}$. All PCR products were analyzed by ethidium bromide-stained agarose gel electrophoresis.

\section{Western Blotting}

C6 and C6-CMV-NIS (or C6-CMV-Luc) and C6-5HRE-NIS (or C6-5HRE-Luc) reporter cells were incubated in a normoxic or hypoxic chamber $\left(<1 \% \mathrm{O}_{2}\right)$ for $24 \mathrm{~h}$, washed with PBS, harvested by scraping, and centrifuged at $15,000 \mathrm{rpm}, 4^{\circ} \mathrm{C}$, for $3 \mathrm{~min}$. Nuclear protein (for HIF-1 $\alpha$ ) and cytoplasmic proteins (for $\alpha$-tubulin and $h N I S$ or $L u c$ ) were extracted using a NE-PER Nuclear and Cytoplasmic Extraction Reagents Kit (Pierce Biotech) according to a modification of manufacturer's instructions. Protein concentrations were measured using a BCA Protein Assay Kit (Pierce). Proteins (20 $\mu \mathrm{g})$ were mixed with a sodium dodecyl sulfate sample buffer, boiled at $70^{\circ} \mathrm{C}$ for $10 \mathrm{~min}$, and separated by gradient $(4 \%-12 \%)$ polyacrylamide gel electrophoresis (Invitrogen).

After the proteins were transferred to nitrocellulose membranes (Schleicher \& Schuell) by electroblotting, membranes were blocked with 5\% skim milk in Tris-buffered saline (20 mM Tris, $137 \mathrm{mM}$ sodium chloride, and $0.1 \%$ polysorbate 20 ) at room temperature for $1 \mathrm{~h}$. The membranes were then incubated with monoclonal mouse antihuman/mouse/rat HIF-1 $\alpha$ antibodies (1:1,000 dilution, Clone 241809; R\&D Systems) and monoclonal mouse antihuman NIS (1:2,000 dilution, Clone FP5A; LAB VISION) (23) or monoclonal mouse anti-luciferase (1:1,000 dilution, Clone LUC-1; Sigma) (24) and $\alpha$-tubulin as an internal loading control (1:2,500 dilution, Clone B-5-1-2; Sigma) for $1 \mathrm{~h}$. After the membranes were washed 3 times with Tris-buffered saline, they were incubated with secondary antimouse horseradish peroxidase-conjugated antibody (1:2,000 dilution) for $1.5 \mathrm{~h}$. Immunoreactive bands were visualized using enhanced chemiluminescence reagents (Roche) and LAS-3000 (Fuji Film).

\section{Generation of Tumor Xenografts in Nude Mice}

All procedures involving animals were approved by the Institutional Animal Care and Use Committee at Seoul National University and were consistent with the Guide for the Care and Use of Laboratory Animals (25).

Three groups of adult male BALB/c nu/nu mice weighing $20 \mathrm{~g}$ on average were used to develop in vivo models of tumor tissue hypoxia. The first group $(n=5)$ was used to visualize DFO-induced HIF-1 transcriptional activity in tumor xenografts using a scintigraphic imaging system (NIS group 1). The second group $(n=4)$ was used to visualize HIF-1 transcriptional activity in natural hypoxic region by growing tumors using a scintigraphic imaging system (NIS group 2). In NIS group 3, different cell lines were implanted as follows: $1 \times 10^{6} \mathrm{C} 6$ cells in the right shoulder, $1 \times 10^{6}$ C6-CMV-NIS cells in the left thigh, and $1 \times 10^{6}$ C6-5HRE-NIS cells 
in the right thigh (NIS group). Other animals $(n=5)$ were used to visualize HIF-1 transcriptional activity using a bioluminescence imaging system; 3 different cell lines were injected subcutaneously as follows: $1 \times 10^{6} \mathrm{C} 6$ cells in the right shoulder, $1 \times 10^{6} \mathrm{C} 6-\mathrm{CMV}$ Luc cells in the left thigh, and $1 \times 10^{6}$ C6-5HRE-Luc cells in the right thigh ( $L u c$ group).

Tumor xenografts $(<1 \mathrm{~cm}$ in diameter) had developed $2 \mathrm{wk}$ later, when the mice were imaged to determine prehypoxia (baseline) $h N I S$ and $L u c$ expression levels. The mice were anesthetized by an intraperitoneal injection of ketamine $(53 \mathrm{mg} / \mathrm{kg})$ and xylazine $(12 \mathrm{mg} / \mathrm{kg})$.

\section{In Vivo Scintigraphic and Bioluminescent Imaging}

In the NIS group, 30 min after an introperitoneal injection of 11.1 $\mathrm{MBq}(300 \mu \mathrm{Ci})$ of ${ }^{99 \mathrm{~m}} \mathrm{Tc}$-pertechnetate per mouse, the mice were placed in a spread-prone position and scanned with a $\gamma$-camera $(\mathrm{ON}$ 410; Ohio Nuclear) equipped with a 6-mm-sized pinhole collimator.

In the $L u c$ group, mice were injected intraperitoneally with an aqueous solution of the Luc substrate luciferin $(5 \mathrm{mg} / \mathrm{mouse}$; Molecular Probes) $10 \mathrm{~min}$ before bioluminescence imaging. Mice were anesthetized with isoflurane and transferred into a light-tight chamber equipped with a charge-coupled device camera (IVIS200; Xenogen Corp.) running Live Image software (Xenogen Corp.) to obtain bioluminescent images.

In NIS group 1 and the $L u c$ group, to enhance the transcriptional activation of HIF-1 transiently, hypoxia-mimicking DFO was injected intraperitoneally at $300 \mathrm{mg} / \mathrm{kg}(26,27)$. Mice were imaged using a $\gamma$-camera (or a charge-coupled device camera) 4, 24, and 48 $\mathrm{h}$ after DFO administration. In NIS group 2, xenografts were grown up to $2 \mathrm{~cm}$ in diameter (for $3 \mathrm{wk}$ ) to develop a natural hypoxic region. Scintigraphic images were acquired sequentially during tumor growth.

\section{Biodistribution, Autoradiography, and Immunohistochemistry (IHC)}

IHC and autoradiography were performed after tumors had been grown for $3 \mathrm{wk}$ to compare reporter protein expression with hypoxic regions.

In NIS group $2(n=4)$, biodistribution studies, phosphor plate digital autoradiography, and IHC study were performed to compare the intratumoral distributions of ${ }^{99 \mathrm{~m}} \mathrm{Tc}$-pertechnetate and pimonidazole (a chemical adduct that detects tissue hypoxia). Ninety minutes before sacrifice, each mouse in NIS group 2 was administered a $0.1-\mathrm{mL}$ injection $(60 \mathrm{mg} / \mathrm{kg}$ of body weight intraperitoneally) of pimonidazole hydrochloride (Hypoxyprobe-1 Plus Kit; Chemicon International), according to the manufacturer's instructions (12). Thirty minutes before sacrifice, ${ }^{99 \mathrm{~m}} \mathrm{Tc}$-pertechnetate (about $37 \mathrm{MBq}$ in $0.1 \mathrm{~mL}$ ) was injected intraperitoneally into each mouse. After sacrifice, the entire tumors were removed, weighed, and measured for radioactivity, and percentages of injected dose per gram $(\% \mathrm{ID} / \mathrm{g})$ of tumor were calculated. Tumors were then snapfrozen, sectioned into 20- $\mu \mathrm{m}$ (for autoradiography) or 4- $\mu \mathrm{m}$ (for hematoxylin and eosin and IHC) slices, and immunostained with fluorescein isothiocyanate (FITC)-conjugated primary antibody against pimonidazole (1:50) and horseradish peroxidase-labeled secondary anti-FITC monoclonal antibody (1:50) supplied with the kit used (Hypoxyprobe-1 Plus Kit), according to a modification of the manufacturer's instructions as described previously (12).

In the $L u c$ group, mice were sacrificed 90 min after being injected with pimonidazole hydrochloride. Serial sections of C6-5HRE-Luc tumor paraffin blocks were cut at $4 \mu \mathrm{m}$, freed of paraffin in HistoClear
(National Diagnostics), and rehydrated through decreasing concentrations of ethanol $(100 \%$ and $95 \%)$. After autoclave treatment ( $3 \mathrm{~min}$ at $121^{\circ} \mathrm{C}$ ), endogenous peroxidase activity was quenched with $3 \% \mathrm{H}_{2} \mathrm{O}_{2}$ in methanol for $5 \mathrm{~min}$ at room temperature. This was followed by rinsing in Tris-buffered saline for $2 \mathrm{~min}$ at room temperature. To obtain pimonidazole staining, sections were first incubated with an FITC-conjugated primary antibody against pimonidazole (1:50 dilution; Hypoxyprobe-1 Plus Kit) for $1 \mathrm{~h}$ at room temperature, then with a horseradish peroxidase-labeled secondary anti-FITC monoclonal antibody (1:50 dilution; Hypoxyprobe-1 Plus Kit) for $30 \mathrm{~min}$ at room temperature, as described previously (12). To obtain luciferase staining, sections were first incubated with a goat antifirefly luciferase polyclonal antibody (1:50 dilution; Abcam Ltd.) for $1 \mathrm{~h}$ at room temperature, then with a biotin-coupled antigoat secondary antibody (1:500 dilution; DAKO) for $30 \mathrm{~min}$ at room temperature. Finally, sections were incubated with streptavidin conjugated with horseradish peroxidase (1:400 dilution; DAKO). To reveal the peroxidase activity, 3,3'-diaminobenzidine was used as chromogenes. Then samples were slightly counterstained with hematoxylin.

\section{Data Analysis}

Quantitation of in vivo scintigraphic and bioluminescent images was performed by using an image-analysis program (Multi Gauge, version 2.02; Fuji Film). Regions of interest (ROIs) were drawn on each scintigraphic and bioluminescent image to quantify radionuclide uptake or the optical flux (photons/s) of the target signal. The same size of ROI was selected for comparison. Statistical significances of all in vitro and biodistribution results were determined using a 2 -sided Student $t$ test with equal variances. The ROI results for NIS group 2 and the $L u c$ group in vivo imaging were determined using a paired $t$ test. A value of $P$ less than 0.05 was considered significant. All statistical analysis was performed using Excel 2003 (Microsoft).

\section{RESULTS}

\section{Establishment of Hypoxia-Sensitive HIF-1-Specific Reporter Gene Systems}

Time- and concentration-dependent increases in radioactivity (or bioluminescence signals) were achieved in C65HRE-NIS (or C6-5HRE-Luc) stable cells under hypoxia. A 3-fold increase of radioactivity in C6-5HRE-NIS cells was observed after $24 \mathrm{~h}$ of hypoxic chamber incubation $(<1 \%$ $\mathrm{O}_{2}$ ) (Fig. 2A) or treatment with $100 \mu \mathrm{M}$ DFO (Fig. 2B), compared with that in C6-5HRE-NIS cells after $24 \mathrm{~h}$ of normoxic chamber incubation or treatment with $0 \mu \mathrm{M}$ DFO. Similar high levels of bioluminescence signal ( $\sim 5$-fold) increases were observed in C6-5HRE-Luc cells after $12 \mathrm{~h}$ of incubation in a hypoxic chamber (Fig. 2C) or after $24 \mathrm{~h}$ of treatment with $100 \mu \mathrm{M}$ DFO (Fig. 2D), compared with that in C6-5HRE-Luc cells after $12 \mathrm{~h}$ of normoxic chamber incubation or after $24 \mathrm{~h}$ of treatment with $0 \mu \mathrm{M}$ DFO $(P<0.001$ and $P<0.0001$ for $*$ and $* *$, respectively, in Fig. 2$)$. Results were normalized versus viable cell numbers. Despite normalization to living cells, the other cells were somewhat damaged by a high concentration of DFO (200 and $400 \mu \mathrm{M})$. These damaged cells responded less to hypoxic conditions. Similar patterns of radioactivity (or bioluminescence signal) induction were observed in human hepatoma SK-Hep 1 cells 

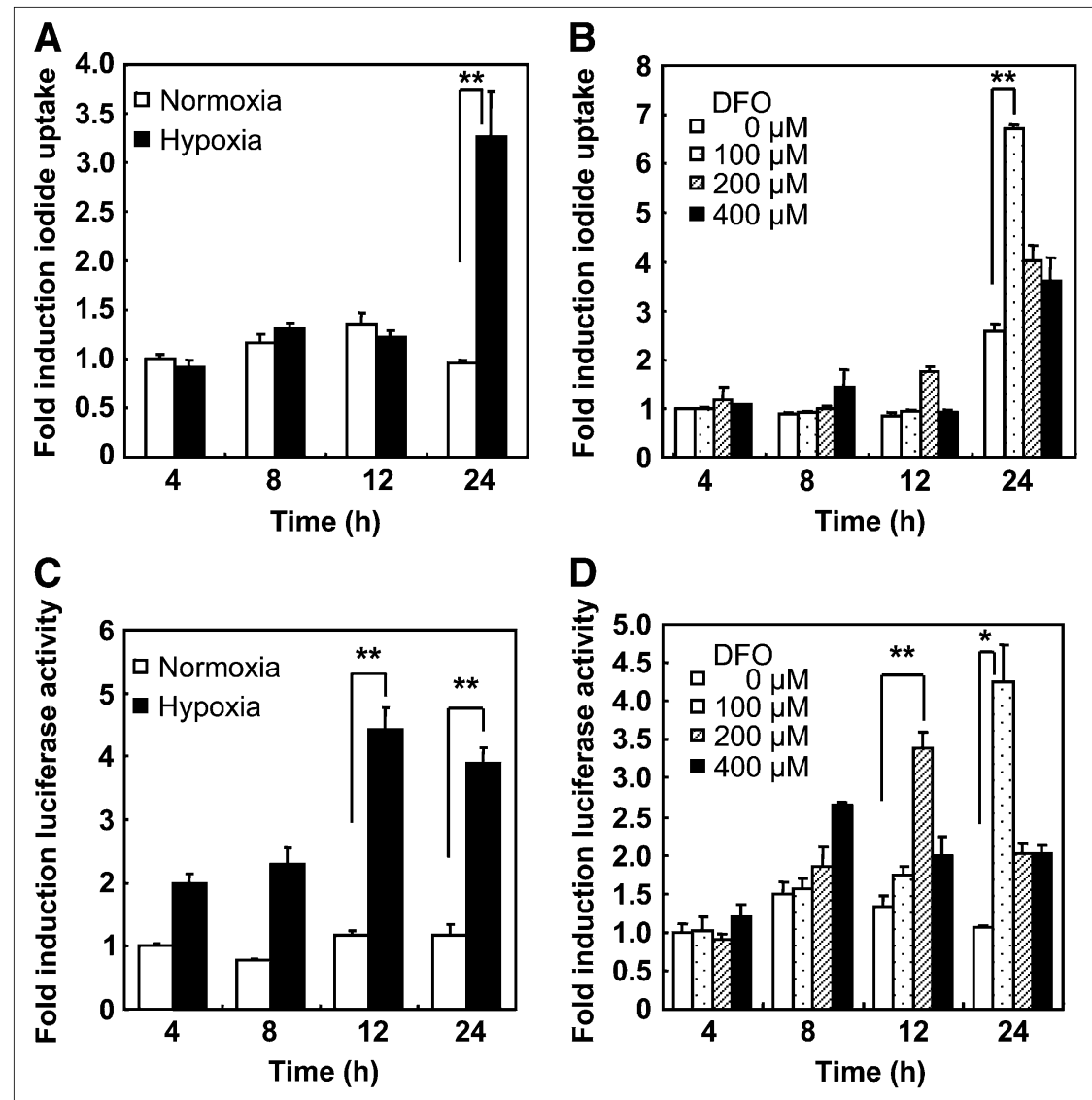

FIGURE 2. In vitro effect of hypoxia on activities of reporter proteins according to radioiodide uptake and luciferase assay. C6-5HRE-NIS or C6-5HRE-Luc cells were seeded in 24-well plates and exposed to normoxia or low atmospheric oxygen $\left(<1 \% \mathrm{O}_{2}\right)(\mathrm{A}$ and $\mathrm{C})$ or various concentrations $(0-400 \mu \mathrm{M})$ of DFO, which mimic hypoxia, for various times (4-24 h) (B and D). Effect of hypoxia on hNIS activities was measured using radioiodide uptake assays in $\mathrm{C} 6-5 \mathrm{HRE}-$ NIS cells ( $A$ and $B$ ), and luciferase activity was assessed using luciferase assays in C6-5HRE-Luc cells (C and D). Radioiodine uptake and bioluminescent intensity were normalized by measuring cell viabilities using trypan blue assay. ${ }^{*} P<$ $0.001 ;{ }^{* \star} P<0.0001$. transfected with p5HRE-NIS (or p5HRE-Luc) (data not shown).

RT-PCR analysis (Fig. 3A) showed marked VEGF and hNIS (or Luc) induction controlled by 5HRE in C6-5HRENIS or C6-5HRE-Luc cells after $24 \mathrm{~h}$ of incubation in a hypoxic chamber. But no change was observed in C6-CMVNIS or C6-CMV-Luc cells under normoxic and hypoxic conditions, and no expression of $h N I S$ (or $L u c$ ) was observed in C6 cells.
Western blot analysis (Fig. 3B) showed that the expressions of stable HIF- $1 \alpha$ proteins, translocated to the nucleus, increased strongly in reporter cells incubated for $24 \mathrm{~h}$ in a hypoxic chamber versus reporter cells under normoxic conditions. In addition, hNIS or Luc expression increased in reporter cells after $24 \mathrm{~h}$ of hypoxic chamber incubation, but no change was observed in the expression of $\alpha$-tubulin, which was used as an internal control. We also observed hNIS (or Luc) mRNA and protein level even under normoxic condi-

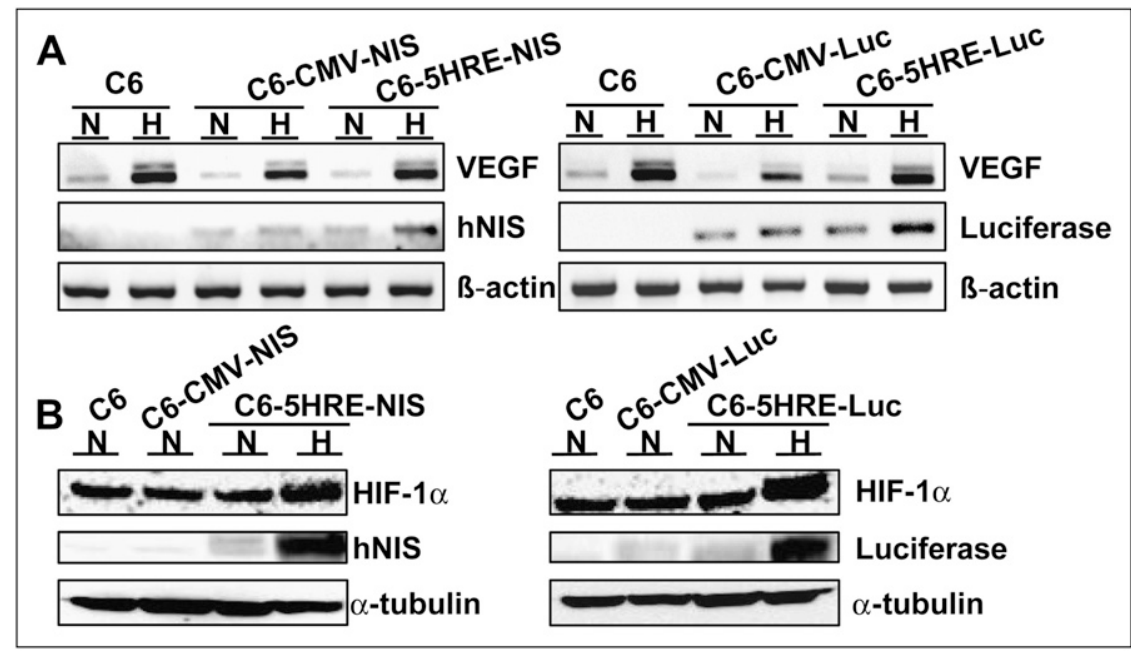

FIGURE 3. Induction of HIF- $1 \alpha$ and HIF1 target genes. (A) RT-PCR analysis of transcripts from HIF-1 target genes, VEGF, and $h N I S$ or Luc reporter genes in normoxic $(\mathrm{N})$ or hypoxic $(\mathrm{H}) \mathrm{C} 6$ and $\mathrm{C6}$ CMV-NIS or C6-CMV-Luc and C6-5HRENIS or C6-5HRE-Luc reporter cells. Cells were incubated under $\mathrm{N}$ or $\mathrm{H}\left(<1 \% \mathrm{O}_{2}\right)$ conditions for $24 \mathrm{~h}$, and then semiquantitative RT-PCR was performed on total RNA. (B) Western blotting of HIF-1 $\alpha$ and reporter proteins in $\mathrm{C} 6$ and $\mathrm{C} 6-\mathrm{CMV}-\mathrm{NIS}$ or C6-CMV-Luc and C6-5HRE-NIS or C6-5HRE-Luc cells. Nuclear protein was used to detect HIF- $1 \alpha$, and $\alpha$-tubulin was used as loading control. 
tions, suggesting 5HRE promoter leakiness for both reporter gene systems.

\section{Reporter Gene Imaging That Visualized Transcription-Activated HIF-1}

In the $L u c$ group, the bioluminescent signal of C6-5HRELuc tumors, versus DFO-pretreated images, time-dependently increased. The bioluminescent signal was not significantly elevated in C6 or C6-CMV-Luc tumors (Fig. 4A).

In NIS group 1, the tracer uptake of C6-5HRE-NIS tumors increased after DFO treatment, compared with at baseline (Fig. 5A), but this difference was not statistically significant. In naturally occurring hypoxic mouse models, NIS group 2, the radioactivities of growing hypoxic C6-5HRE-NIS tumors $(2 \mathrm{~cm}$ in diameter) significantly increased versus the radioactivities of prehypoxic C6-5HRE-NIS tumors $(1 \mathrm{~cm}$ in diameter). However, radioactivity decreased in C6-CMVNIS tumors in the NIS group (Fig. 5B).

ROI analysis of bioluminescence images showed a 2- or 3 -fold increase in signal at 4 or $24 \mathrm{~h}$ after DFO treatment in C6-5HRE-Luc xenografts versus pre-DFO tumors $(P<0.05)$ (Fig. 4B). In NIS group 2, a 2-fold increase in radioactivity was observed in naturally hypoxic regions in C6-5HRE-NIS tumors of $2 \mathrm{~cm}$ in diameter versus prehypoxic tumors of less than $1 \mathrm{~cm}$ in diameter $(P<0.005)$ (Fig. 5C). Tumors were studied at histology hematoxylin and eosin staining (data not shown), and then hypoxic portions were observed in tumor sections after scintigraphic and bioluminescence imaging.

\section{Biodistribution and Comparison Between Autoradiography and IHC}

In the biodistribution of ${ }^{99 \mathrm{~m}} \mathrm{Tc}-$ pertechnetate in mice $(n=4)$ of NIS group 2, C6-5HRE-NIS tumors accumulated more radioactivity $(24.82 \pm 3.98 \% \mathrm{ID} / \mathrm{g})$ than $\mathrm{did} \mathrm{C} 6(2.85 \pm$ $0.59 \% \mathrm{ID} / \mathrm{g})$ or C6-CMV-NIS $(12.3 \pm 3.08 \% \mathrm{ID} / \mathrm{g})$ tumors (Fig. 5D) $(P<0.005)$. Autoradiography of ${ }^{99 m} \mathrm{Tc}-$ pertechnetate (Fig. 6F) and IHC staining of pimonidazole (Fig. 6D) in C6-5HRE-NIS tumors demonstrated localization of accumulating radioactivity similar to that observed for pimonidazole. In C6-5HRE-Luc tumor sections, patterns of IHC staining were similar for pimonidazole (Fig. 6E) and luciferase (Fig. 6G). However, ${ }^{99 \mathrm{~m} T c-p e r t e c h n e t a t e}$ uptake was low in control C6 gliomas (Fig. 6A) stained negatively for $L u c$. The results of autoradiography and IHC implied that $h N I S$ or $L u c$ reporter genes were specifically expressed in hypoxic regions.

\section{DISCUSSION}

In this study, 2 different reporter gene systems were developed, controlled by 5HRE, to evaluate HIF-1 transcriptional activity. In addition, in vitro tests, in vivo small-animal studies, and biodistribution, autoradiography, and IHC experiments were performed.
FIGURE 4. Bioluminescence imaging of HIF-1 transcriptional activation in tumors of Luc group. (A) Control image (no DFO treatment) was acquired 2 wk after tumor challenge $(\mathrm{a}=\mathrm{C} 6, \mathrm{~b}=\mathrm{C6}-\mathrm{CMV}$-Luc, and $c=$ C6-5HRE-Luc), and then images were sequentially obtained at 4 and $24 \mathrm{~h}$ after systemic injection of DFO. (B) ROls were drawn on bioluminescence images to quantify photon fluxes per second. Statistical significances of $\mathrm{ROI}$ results were determined using paired $t$ test. Timedependent increases in bioluminescent signals were detected. ${ }^{*} P<0.05$.

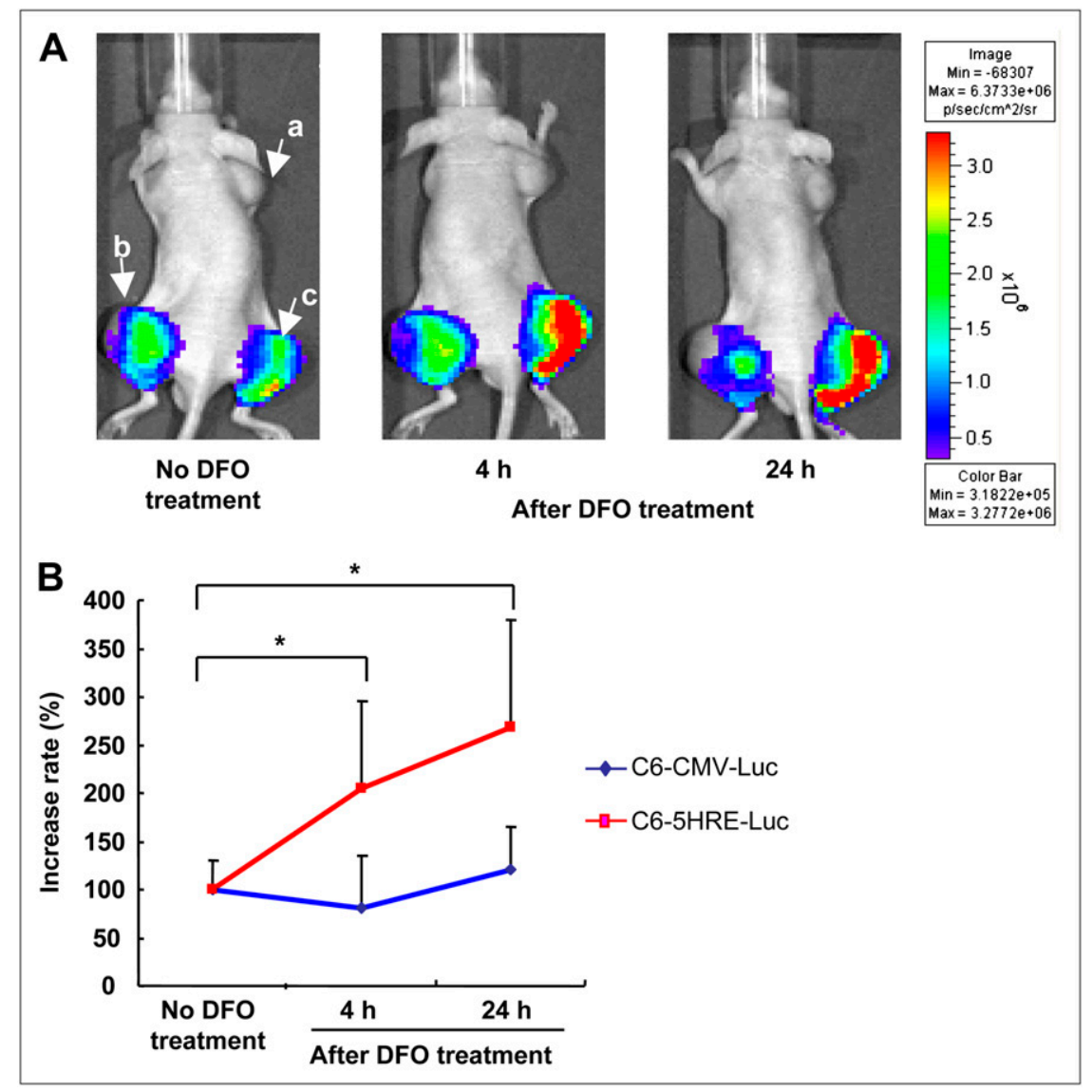




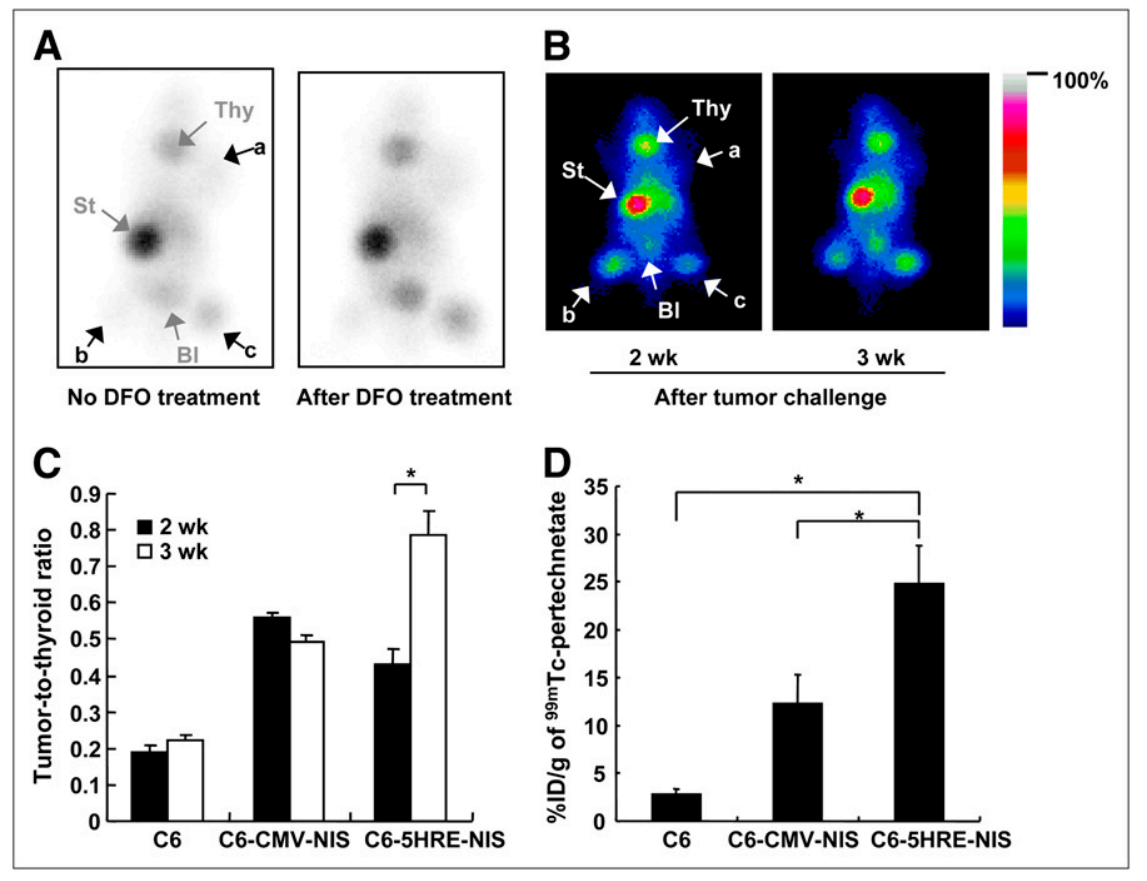

FIGURE 5. Scintigraphic imaging of HIF-1 transcriptional activation in NIS group tumors. (A) Scintigraphic imaging of NIS group 1. In NIS group 1, control scintigraphic image (no DFO treatment) was acquired 2 wk after tumor challenge ( $\mathrm{a}=\mathrm{C} 6, \mathrm{~b}=\mathrm{C6}-\mathrm{CMV}-\mathrm{NIS}, \mathrm{c}=\mathrm{C6}-$ 5HRE-NIS, Thy = thyroid, St = stomach, $\mathrm{BI}=$ bladder), and post-DFO image was observed $24 \mathrm{~h}$ after administering DFO intraperitoneally. (B) Scintigraphic imaging of NIS group 2. In another hypoxiainduced NIS group 2, tumors were grown for 3 wk (diameter, $2 \mathrm{~cm}$ ) to allow hypoxia to occur naturally. (C) ROls on scintigraphic images of NIS group 2. ROls of thyroid and tumor were drawn on scintigraphic images from $B$. Tumor or thyroid ratio was calculated for individual mice $(n=4)$. Statistical significances of ROI results were determined using paired $t$ test. Scintigraphic signal in 3-wk C65HRE-NIS tumors was significantly higher than in 2-wk tumors, whereas no significant change was detected in $\mathrm{C} 6$ or C6-CMV-NIS tumors. ${ }^{\star} P<0.005$. (D)

Biodistribution of $99 \mathrm{mTc}$-pertechnetate in mice of NIS group 2. After final imaging, tumors were excised, and \%ID/g values for $99 \mathrm{~m}$ Tc-pertechnetate in each tumor were calculated $(n=4)$. Statistical significances of biodistribution results were determined using 2-sided Student $t$ test with equal variances. Radioactivities in C6-5HRE-NIS tumors were significantly greater than those in $\mathrm{C} 6$ and $\mathrm{C} 6-\mathrm{CMV}-\mathrm{NIS}$ tumors. Bars indicate mean $\pm \mathrm{SD}$. ${ }^{\star} P<0.005$.

The establishment of an HIF-1-specific reporter system was confirmed by in vitro experiments. Western blot analysis using HIF- $1 \alpha$ nuclear protein verified that posttranslationally modified HIF- $1 \alpha$ protein was translocated to the nucleus under hypoxic conditions. RT-PCR demonstrated the increased expression of HIF-1-induced nuclear or bioluminescent imaging reporter genes ( $h N I S$ or $L u c$ ) and of hypoxia response genes, such as $V E G F$. The increased activity of functional translated reporter proteins was monitored under hypoxia by measuring radioactivity and bioluminescent intensity. Although many experiments have found no detectable increase in HIF- $1 \alpha$ mRNA under hypoxic conditions, the mRNA levels of many hypoxia-responsive target genes were found to be significantly elevated $(28,29)$; thus, there was no need to confirm the transcriptional regulation of the HIF- $1 \alpha$ gene under hypoxic conditions in the present study.

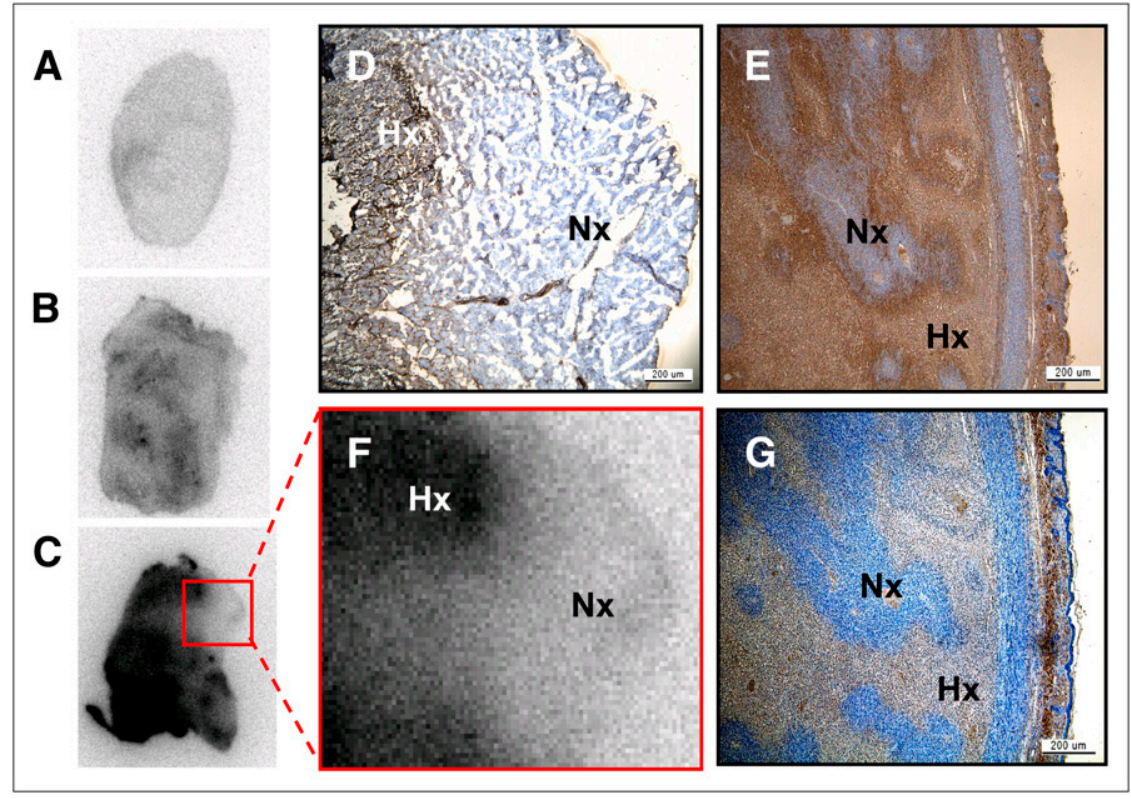

FIGURE 6. Comparison between 99mTc autoradiography and pimonidazole staining of tumors in NIS group 2 and immunohistochemical staining for pimonidazole and luciferase in Luc group. This autoradiograph of C6-5HRE-NIS tumor section (C) has higher ${ }^{99 \mathrm{~m} T c}$ intensity than C6 (A) or C6-CMV-NIS (B) tumor sections. F shows square area in $\mathrm{C}$ at higher magnification. Immunohistochemical staining $(\times 40)$ pattern observed using antipimonidazole antibody (D) shows similar distribution of $99 \mathrm{mTc}$ in 3-wk-grown C6-5HRE-NIS tumor section (F). Colocalization immunohistochemical study $(\times 40)$ for hypoxic marker, pimonidazole $(E)$, and reporter protein, luciferase (G), was performed using 3-wk-grown C6-5HRE-Luc tumors in Luc group. Hypoxic areas as defined by pimonidazole-positive staining in $E$ were similar to luciferase-positive areas in $\mathrm{G}$. $\mathrm{Nx}=$ normoxic region; $\mathrm{Hx}=$ hypoxic region. Bars indicate $200 \mu \mathrm{m}$. 
In vivo scintigraphy and bioluminescence images showed elevated HIF-1 transcriptional activity after DFO treatment. In addition, in line with natural tumor growth, scintigraphy showed increased C6-5HRE-NIS, compared with C6-CMVNIS, tumor radioactivity. These results hold true in in vitro as well as in vivo studies (data not shown).

However, our reporter systems still have some limitations. At first, our reporter system showed a leaky reporter gene expression even under normoxic conditions. Harada et al. constructed a $L u c$ gene fused with the oxygen-dependent degradation (ODD) domain, which is controlled under the 5HRE promoter (5HREp-ODD-Luc), to improve this problem of the promoter leakiness of a 5HRE promoter (30). Second, the CMV promoter, compared with the 5HRE construct, had a weak signal in vitro and in vivo. The reason might be that it takes a long time to establish C6-CMV-Luc or C6-CMV-NIS stable cells, which undergo more passages than C6-5HRE-Luc or C6-5HRE-NIS cells. We already reported that gene silencing based on methylation of $\mathrm{CpG}$ sites and histone deacetylation in CMV constructs might result in the decrease of transgene $h N I S$ gene expression after several passages and could be reversed by DNA demethylation and histone deacetylation inhibition (31). Third, the low sensitivity of NIS reporter genes explains the lack of a significant increase in DFO-induced scintigraphic images versus DFO-induced bioluminescent images $(19,32)$. And the higher accumulations of ${ }^{99 \mathrm{~m}} \mathrm{Tc}-$ pertechnetate observed in naturally occurring hypoxic tumors, compared with DFOinduced tumors in the NIS group, is probably explained by the different effects of long-term hypoxia for $1 \mathrm{wk}$ and transient DFO treatment. There appeared to be a yet undefined threshold of HIF-1 activation below which p5HRE-NIS expression was not detected, and we did not confirm that the degree of HIF-1 activation is correlated with the degree of promoter activation.

Two different imaging systems, which have their own advantages and disadvantages, were used with the hNIS and $L u c$ reporter genes. Although bioluminescence imaging is technically simple and highly sensitive with minimal background interference $(19,32)$, it is of limited use in largeanimal studies, especially in human applications, because of light absorption by tissue (33). On the other hand, the nuclear medicine imaging reporter gene NIS is applicable in large animals and humans. Moreover, although NIS has low sensitivity, compared with the luciferase system, it has advantages such as ready availability and no requirement for complicated radiochemistry of its substrates, such as radioiodine or ${ }^{99 \mathrm{~m}} \mathrm{Tc}$-pertechnetate, which can be used in place of iodide. In addition, the metabolic clearances of these substrates are well understood, and these substrates are known not to induce an immune response (18).

In this study, ex vivo immunohistochemical staining and autoradiography suggested that increased imaging signals, that is, radioactivities and bioluminescent intensities, in tumors were induced by increased imaging reporter gene expressions, which were stimulated under hypoxic condi- tions. Autoradiography and IHC of C6-5HRE-NIS tumors demonstrated that the localization of accumulated radioactivity was similar to that of pimonidazole (the hypoxic region), which implies that the $h N I S$ reporter system controlled by 5HRE specifically undergoes transcriptional regulation via HIF-1 activation. The immunostaining study of C6-5HRE-Luc tumors showed concordance between luciferase and pimonidazole staining findings and thus demonstrated $L u c$ gene expression in hypoxic tumor regions.

Visualization of hypoxic tumors is quite important in the management of cancer with chemotherapy or radiotherapy. Hypoxic tumors are usually resistant to chemotherapy or radiotherapy. In the visualization of tumor hypoxia, these reporter imaging systems differ in several aspects from conventional hypoxic PET images obtained using ${ }^{18}$ F-fluoromisonidazole, ${ }^{60} \mathrm{Cu}$-diacetyl-bis $\left(N^{4}\right.$-methythiosemicarbazone), or others, which concern binding to macromolecules in hypoxic cells. In our system, exogenous gene transfection is needed, which presents difficulties in practice. However, hypoxic PET images can visualize hypoxic areas only and tissue hypoxia is only 1 stimulator of HIF-1 activation. Several other tumor factors, such as growth factors, cytokines, and reactive oxygen species induced by ionizing radiation $(34,35)$, also stimulate HIF- $1 \alpha$ activation. These factors control the transcriptions of several genes involved in cancer biology, for example, in angiogenesis, cell survival, glucose metabolism, and invasion (4). In addition, it has been suggested that not only hypoxia but also sensitivity of tumor vasculature to radiation is a major determinant of response to radiotherapy. Successful radiotherapy is dependent on the destruction of the tumorfeeding vasculature, as the survival of tumors is highly reliant on vessels. Activation of HIF-1 itself leads to radioresistance by inducing the expression of $V E G F$, erythropoietin, transforming growth factor- $\beta 3$, plasminogen activator inhibitor-1, and transferrin genes, which are highly active in angiogenesis. Moreover, radiotherapy upregulates HIF-1 levels and activity of tumor cells because of reactive oxygen species by radiation-induced tumor reoxygenation (34). Therefore, the visualization and tumor therapy targeting for HIF-1 activation is more important than that for hypoxia itself when assessing cancer behavior. Reporter gene imaging might offer a novel means of investigating molecular-genomic events in cancer.

\section{CONCLUSION}

We developed HIF-1-specific bioluminescence and scintigraphic imaging systems in tumors. This is the first study, to our knowledge, to visualize HIF-1 transcriptional activation using $h N I S$, a nuclear medicine imaging reporter gene that is applicable in large animals and humans. These noninvasive imaging tools can be used to investigate HIF-1-associated molecular-genomic events and could be used to predict the effects of chemotherapy and radiotherapy in cancer. 


\section{ACKNOWLEDGMENT}

This work was supported by grant 03-2007-006 from the Seoul National University Hospital research fund (2007).

\section{REFERENCES}

1. Wang GL, Semenza GL. Purification and characterization of hypoxia-inducible factor 1. J Biol Chem. 1995;270:1230-1237.

2. Unruh A, Ressel A, Mohamed HG, et al. The hypoxia-inducible factor- $1 \alpha$ is a negative factor for tumor therapy. Oncogene. 2003;22:3213-3220.

3. Lungu GF, Li ML, Xie X, Wang LV, Stoica G. In vivo imaging and characterization of hypoxia-induced neovascularization and tumor invasion. Int J Oncol. 2007; 30:45-54.

4. Semenza GL. Targeting HIF-1 for cancer therapy. Nat Rev Cancer. 2003;3:721-732.

5. Pouyssegur J, Dayan F, Mazure NM. Hypoxia signalling in cancer and approaches to enforce tumour regression. Nature. 2006;441:437-443.

6. Berra E, Ginouves A, Pouyssegur J. The hypoxia-inducible-factor hydroxylases bring fresh air into hypoxia signalling. EMBO Rep. 2006;7:41-45.

7. Ivan M, Kondo K, Yang H, et al. HIF $\alpha$ targeted for VHL-mediated destruction by proline hydroxylation: implications for $\mathrm{O}_{2}$ sensing. Science. 2001;292:464-468.

8. Maxwell PH, Wiesener MS, Chang GW, et al. The tumour suppressor protein VHL targets hypoxia-inducible factors for oxygen-dependent proteolysis. Nature. 1999;399:271-275.

9. Semenza GL. Regulation of mammalian $\mathrm{O}_{2}$ homeostasis by hypoxia-inducible factor 1. Annu Rev Cell Dev Biol. 1999;15:551-578.

10. Semenza GL. Perspectives on oxygen sensing. Cell. 1999;98:281-284.

11. Cardenas-Navia LI, Yu D, Braun RD, Brizel DM, Secomb TW, Dewhirst MW. Tumor-dependent kinetics of partial pressure of oxygen fluctuations during air and oxygen breathing. Cancer Res. 2004;64:6010-6017.

12. Samoszuk MK, Walter J, Mechetner E. Improved immunohistochemical method for detecting hypoxia gradients in mouse tissues and tumors. $J$ Histochem Cytochem. 2004;52:837-839.

13. Kang SH, Cho HT, Devi S, et al. Antitumor effect of 2-methoxyestradiol in a rat orthotopic brain tumor model. Cancer Res. 2006;66:11991-11997.

14. Kaluz S, Kaluzova M, Stanbridge EJ. Expression of the hypoxia marker carbonic anhydrase IX is critically dependent on SP1 activity: identification of a novel type of hypoxia-responsive enhancer. Cancer Res. 2003;63:917-922.

15. Blanco Pampin J, Garcia Rivero SA, Otero Cepeda XL, Vazquez Boquete A, Forteza Vila J, Hinojal Fonseca R. Immunohistochemical expression of HIF$1 \alpha$ in response to early myocardial ischemia. J Forensic Sci. 2006;51:120-124.

16. Wen B, Burgman P, Zanzonico P, et al. A preclinical model for noninvasive imaging of hypoxia-induced gene expression: comparison with an exogenous marker of tumor hypoxia. Eur J Nucl Med Mol Imaging. 2004;31:1530-1538.

17. Liu J, Qu R, Ogura M, Shibata T, Harada H, Hiraoka M. Real-time imaging of hypoxia-inducible factor-1 activity in tumor xenografts. J Radiat Res (Tokyo). 2005;46:93-102.

18. Chung JK. Sodium iodide symporter: its role in nuclear medicine. J Nucl Med. 2002;43:1188-1200.
19. Shin JH, Chung JK, Kang JH, et al. Noninvasive imaging for monitoring of viable cancer cells using a dual-imaging reporter gene. J Nucl Med. 2004; 45:2109-2115.

20. Kim KI, Chung JK, Kang JH, et al. Visualization of endogenous p53-mediated transcription in vivo using sodium iodide symporter. Clin Cancer Res. 2005; 11:123-128

21. Jeong $\mathrm{CH}$, Lee YM, Choi KS, et al. Hypoxia-responsive element-mediated soluble Tie2 vector exhibits an anti-angiogenic activity in vitro under hypoxic condition. Int J Oncol. 2005;26:211-216.

22. Weiss SJ, Philp NJ, Grollman EF. Iodide transport in a continuous line of cultured cells from rat thyroid. Endocrinology. 1984;114:1090-1098.

23. Castro MR, Bergert ER, Beito TG, McIver B, Goellner JR, Morris JC. Development of monoclonal antibodies against the human sodium iodide symporter: immunohistochemical characterization of this protein in thyroid cells. J Clin Endocrinol Metab. 1999;84:2957-2962.

24. de Wet JR, Wood KV, DeLuca M, Helinski DR, Subramani S. Firefly luciferase gene: structure and expression in mammalian cells. Mol Cell Biol. 1987;7:725737.

25. Guide for the Care and Use of Laboratory Animals. Washington, DC: National Academy Press; 1996.

26. Prass K, Ruscher K, Karsch M, et al. Desferrioxamine induces delayed tolerance against cerebral ischemia in vivo and in vitro. J Cereb Blood Flow Metab. 2002;22:520-525.

27. Bergeron M, Gidday JM, Yu AY, Semenza GL, Ferriero DM, Sharp FR. Role of hypoxia-inducible factor-1 in hypoxia-induced ischemic tolerance in neonatal rat brain. Ann Neurol. 2000;48:285-296.

28. Huang LE, Arany Z, Livingston DM, Bunn HF. Activation of hypoxia-inducible transcription factor depends primarily upon redox-sensitive stabilization of its alpha subunit. J Biol Chem. 1996;271:32253-32259.

29. Kallio PJ, Pongratz I, Gradin K, McGuire J, Poellinger L. Activation of hypoxiainducible factor $1 \alpha$ : posttranscriptional regulation and conformational change by recruitment of the Arnt transcription factor. Proc Natl Acad Sci USA. 1997;94:5667-5672.

30. Harada H, Kizaka-Kondoh S, Itasaka S, et al. The combination of hypoxiaresponse enhancers and an oxygen-dependent proteolytic motif enables real-time imaging of absolute HIF-1 activity in tumor xenografts. Biochem Biophys Res Commun. 2007;360:791-796.

31. Kim YH, Lee DS, Kang JH, et al. Reversing the silencing of reporter sodium/ iodide symporter transgene for stem cell tracking. J Nucl Med. 2005;46:305311.

32. So MK, Kang JH, Chung JK, et al. In vivo imaging of retinoic acid receptor activity using a sodium/iodide symporter and luciferase dual imaging reporter gene. Mol Imaging. 2004;3:163-171.

33. Min JJ, Gambhir SS. Gene therapy progress and prospects: noninvasive imaging of gene therapy in living subjects. Gene Ther. 2004;11:115-125.

34. Moeller BJ, Cao Y, Li CY, Dewhirst MW. Radiation activates HIF-1 to regulate vascular radiosensitivity in tumors: role of reoxygenation, free radicals, and stress granules. Cancer Cell. 2004;5:429-441.

35. Semenza GL. Intratumoral hypoxia, radiation resistance, and HIF-1. Cancer Cell. 2004;5:405-406. 